\title{
Impact of Modifiable Risk Factors on the Occurrence of Cutaneous Leishmaniasis in Diyala, Iraq: Case-Control Study
}

Asaad Mahdi Lehlewa ${ }^{1}$, MD, MSc; Hanan Abdulghafoor Khaleel ${ }^{2}$, MD, MSc, DrPH; Faris Lami ${ }^{3}$, MD, PhD; Saif Aldeen Falah Hasan ${ }^{2}$, DVM, HDip; Hasanain Asmail Malick ${ }^{1}$, MD, MSc; Razzaq Hashim Mohammed ${ }^{4}$, MD, MSc; Qais Abdulazziz Abdulmottaleb ${ }^{5}$, MD, MSc

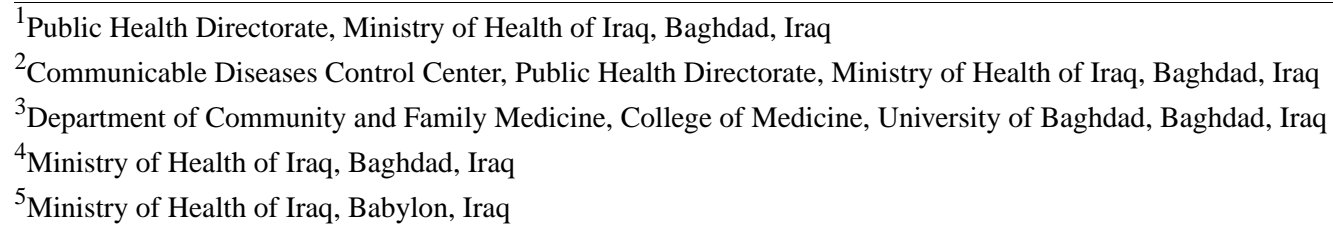

\section{Corresponding Author:}

Hanan Abdulghafoor Khaleel, MD, MSc, DrPH

Communicable Diseases Control Center

Public Health Directorate

Ministry of Health of Iraq

Alandalus Square

Baghdad

Iraq

Phone: 9647901472335

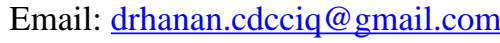

\section{Related Articles:}

Preprint: https://preprints.jmir.org/preprint/28255

Peer-Review Report by Riham Al-Dubaiee (Reviewer O): https://med.jmirx.org/2021/3/e31513/

Peer-Review Report by Rihana Taher (Reviewer R): https://med.jmirx.org/2021/3/e31514/

Peer-Review Report by Abdulkareem Ali Hussein Nassar (Reviewer T): https://med.jmirx.org/2021/3/e31515/

Authors' Response to Peer-Review Reports: https://med.jmirx.org/2021/3/e31512/

\section{Abstract}

Background: In 2018, an outbreak of cutaneous leishmaniasis (CL) occurred in Diyala Province in Iraq. Several risk factors of CL were identified in a prior study; however, the impact of removing modifiable risk factors on the occurrence of the disease was not measured.

Objective: The aim of this study is to measure the impact of removing modifiable risk factors of CL on the occurrence of the disease.

Methods: We conducted a population-based unmatched case-control study in two conveniently selected districts in Diyala Province. All cases of CL were included. Controls were chosen preferentially according to the site where the cases occurred. A structured questionnaire was used to collect data. The unadjusted odds ratios (ORs) and 95\% confidence intervals for each risk factor were calculated using binary logistic regression. We also calculated the attributable fractions and 95\% confidence intervals of the modifiable risk factors. A $P$ value $<.05$ was considered statistically significant.

Results: Data from 844 persons (432 cases, 51.2\%) were analyzed. Cases were more likely than controls to report a history of previous displacement (OR 5.18, 95\% CI 3.84-6.98), electricity supply for less than 12 hours per day (OR 1.94, 95\% CI 1.47-2.55), living in a rural area (OR 1.91, 95\% CI 1.45-2.51), living in a clay house (OR 2.41, 95\% CI 1.59-3.66), having an unpainted indoor living space (OR 2.14, 95\% CI 1.51-3.02), having rodents inside the house (OR 5.15, 95\% CI 3.56-7.47), having chickens, sheep, or both (OR 3.44, 95\% CI 2.48-4.75), having a mixture of dogs and sheep or of dogs and chickens within a distance of less than 100 meters (OR 3.92, 95\% CI 2.59-5.94), fogging (OR 2.11, 95\% CI 1.40-3.19), bed net use (OR 1.72, 95\% CI 1.08-2.72), and sleeping outside or a mixture of inside and outside (OR 4.01, 95\% CI 1.32-12.19). The data show that the exposure of approximately $70 \%$ to $80 \%$ of cases was associated with displacement, the presence of rodents inside the house, the presence of animals within 100 meters of the house, the presence of animals (chickens/sheep/both or a mixture of dogs and sheep or of dogs 
and chickens), and sleeping outside. Approximately 40\%-50\% of the cases reported living in a clay house, living in a rural area, having an unpainted indoor space, having an electricity supply for less than 12 hours, and using a bed net.

Conclusions: Prevention and control of CL requires a multifaceted approach that relies on changing environmental conditions, housing conditions, and human behavior. Fogging and bed net use were not effective because the underlying housing characteristics and human behavior provided a good culture for the disease. We recommend conducting a study to identify the species, reservoirs, and vectors of CL in Iraq; studying vector behaviors before applying environmental control measures; and educating the public on how and when to use bed nets as well as how to accompany their use with behavioral changes.

(JMIRx Med 2021;2(3):e28255) doi: $10.2196 / 28255$

\section{KEYWORDS}

cutaneous leishmaniasis; outbreak; Iraq; risk factors; risk; disease; infectious disease; disease prevention; prevention

\section{Introduction}

Cutaneous leishmaniasis (CL) is a neglected tropical disease for which approximately 500,000 to 1,000,000 new cases are reported per year worldwide [1,2]. Furthermore, it causes an estimated 2.4 million disability-adjusted life years, placing it among the top 10 in a global analysis of infectious diseases [3]. Countries in the Eastern Mediterranean region contribute approximately $57 \%$ of the total CL burden, where Leishmania tropica and Leishmania major are endemic in 18 countries and territories (including Iraq). Moreover, more than 100,000 new cases of CL are reported annually to the World Health Organization by countries in the Eastern Mediterranean region; however, the actual incidence is estimated to be 3 to 5 times higher [1,4,5]. In Iraq, surveillance data after the 1970s showed an average of $10 \mathrm{x} 00$ cases per year [6]. According to internal technical reports released by the Iraqi Ministry of Health, the last country-wide outbreak started at the end of 2014 and continued throughout 2017, when the number of cases per year reached an average of 16,000. In 2018, the number of cases started to decline steadily and reached approximately 11,000 .

There are more than 20 Leishmania species that can be transmitted to humans, and more than 90 sand fly species that can transmit the protozoa to humans; moreover, approximately 70 animal species, including humans, are natural reservoir hosts of Leishmania parasites [7]. The transmission cycle of the parasite in nature can be either zoonotic or anthroponotic $[8,9]$. In Iraq, data are lacking regarding the most common Leishmania species, reservoirs, and vectors. However, evidence from nearby countries suggests that both transmission cycles of CL (zoonotic and anthroponotic) are common in Iraq $[5,10,11]$.

Risk factors for developing CL include residence in rural areas, climate changes, movement of people, conflict areas, deforestation, house characteristics, and human behavior [9,12-14]. Prevention and control of leishmaniasis requires a combination of intervention strategies because transmission occurs in a complex biological system involving the human host, parasite, sand fly vector, and, in some cases, an animal reservoir host. Key strategies for prevention are early diagnosis and effective case management, vector control, effective disease surveillance, control of animal reservoir hosts, and social mobilization and strengthening partnerships among all concerned institutions [14].
Although CL is a self-healing disease, it is potentially disfiguring [1]. The only drug licensed by the Iraqi Ministry of Health to treat CL is sodium stibogluconate, a pentavalent antimony compound.

The recent outbreak affected most Iraqi provinces variably, with an overall incidence rate of $0.9 / 10^{3}$ population. The highest incidence rate was in Diyala Province $\left(4 / 10^{3}\right.$ population), while the lowest incidence rate was in Duhok Province $\left(0.01 / 10^{3}\right.$ population). According to internal reports and discussion with the zoonotic diseases section at the Iraq Communicable Diseases Control Center, the lack of infrastructure and municipal services, the presence of hard-to-reach areas, and a lack of prevention programs were blamed for the occurrence of the outbreak. Diyala was subjected to terrorist and military operations from 2014 to 2016, when most of its residents were displaced. Meanwhile, it also encountered a wave of a Leishmania epidemic that started in November 2014, reached its peak during 2015, and continued throughout 2017. In response to the rapid escalation of the outbreak, the outbreak response team investigated the outbreak to identify possible risk factors and the impact of removing these factors on reducing the number of cases.

\section{Methods}

This is a population-based unmatched case-control study. A case of CL was defined as any person who showed clinical signs (skin or mucosal lesions) and was diagnosed by a dermatologist with CL. A control person was defined as any person (or family member) who was proved to be free of these skin or mucosal lesions. Controls were chosen preferentially according to the site where the cases occurred (from the neighboring house or village). The study was conducted in two conveniently selected districts in Diyala Province (Al-Muqdadiya and Al-Mansuriya). Those two districts were selected as part of the on-job outbreak investigation because surveillance data detected an increase in the number of CL cases in these areas, and those areas were in the recovery process after security instability. Approval for conducting the study was obtained from the Public Health Directorate/Ministry of Health and Diyala Directorate of Health. Oral consent was obtained from the cases and controls themselves or from their caretakers.

Field epidemiology training program students interviewed cases and controls using a modified questionnaire of the case investigation form of the zoonotic section of the Iraq 
Communicable Diseases Control Center. The questionnaire contained questions about the main demographic (age, sex, occupation), clinical (date of onset, signs and symptoms, presence of other cases within the family, treatment, previous visits, number and site of skin lesions), and epidemiological characteristics (displacement history, house and residency data [information about the type of residency area; house construction materials, such as wall type; electricity provided; animals living within the house; painting of indoor areas; presence of rodents inside or around the house]), sleeping habits, and preventive measures implemented in the area (fogging and use of bed nets).

A total of 866 persons were interviewed within the 717 families visited: 451 cases (292 from Al-Mansuriya District and 159 from Al-Muqdadiya District) and 415 controls (182 Al-Mansuriya District and 233 from Al-Muqdadiya District). However, we excluded 22 persons from the sample due to incomplete information. The final sample size used was 844 persons (cases $=432$, controls $=412$ ), with a ratio of almost 1 case to 1 control.

Univariate analysis was used to describe the study sample. Bivariate analysis was used to detect possible associations between each of the risk factors and the disease (CL) using the chi-square test of independence. The unadjusted odds ratio (OR) and $95 \%$ confidence interval of each risk factor were calculated using binary logistic regression. The attributable fractions and their corresponding $95 \%$ CIs were calculated for the modifiable risk factors. A $P$ value $<.05$ was considered statistically significant.

Epi Info, version 7.2 was used for data entry and SPSS, version 25 (IBM Corporation) was used for data analysis.

\section{Results}

Data from 844 persons (432 cases, $51.2 \%$ ) were analyzed. There were no gender differences between cases and controls. Cases were more likely than controls to report a history of previous displacement, electricity supply for less than 12 hours per day, and living in a rural area. Regarding house characteristics, cases were more likely than controls to report living in a clay house, living in unpainted indoor areas, and the presence of rodents inside the house. As for animal ownership and the distances of the animals from the house, cases were more likely than controls to have chickens only, sheep only, or both and a mixture of animals (dogs and sheep or dogs and chickens) within a distance of less than 100 meters. Regarding possible preventive measures, cases were more likely to report fogging, bed net use, and sleeping outside or a mixture of inside and outside than controls.

Almost all the risk factors were statistically significantly associated with higher odds of having CL. Nevertheless, the strength of the association varied, as it was stronger (4 to 5 times higher odds of having CL) for factors such as displacement, having animals within 100 meters of the house, and sleeping outside the house. Factors that were associated with a 2 to 3 times increase in the odds of having CL included living in a clay house, having an unpainted indoor area, sleeping in a mixed pattern (inside and outside the house), having animals (whether chickens only, sheep only, or both, or mixtures of dogs and sheep or dogs and chickens), and, interestingly, using a bed net and fogging/unknown fogging status. In fact, the use of a bed net was associated with $72 \%$ higher odds of having CL in comparison to the lack of use of a bed net (OR 1.72, 95\% CI 1.08-2.72). Likewise, fogging and unknown fogging status were associated with statistically significant 2 -fold higher odds of having CL compared to no fogging $(P<.001)$.

Regarding the impact of removing modifiable risk factors, our results show that approximately $70 \%$ to $80 \%$ of the cases were associated with displacement, the presence of rodents inside the house, the presence of animals within 100 meters of the house, the presence of animals (whether chicken only/sheep only/both or a mixture of dogs and sheep or dogs and chickens), and sleeping outside. Similarly, approximately $40 \%$ to $50 \%$ of the exposure of the cases was associated with living in a clay house; living in a rural area; having an unpainted indoor space; having an electricity supply for less than 12 hours per day; and, interestingly, using a bed net. Unexpectedly, approximately $10 \%$ to $20 \%$ of the exposed cases reported fogging or unknown fogging status. That is, fogging and unknown fogging status were negatively associated with the occurrence of CL.

The characteristics of the study sample are shown in Table 1. The risk factors for $\mathrm{CL}$ in the study population are summarized in Table 2. 
Table 1. Characteristics of the study sample.

\begin{tabular}{|c|c|c|c|c|}
\hline Characteristic & Total $(\mathrm{N}=844), \mathrm{n}(\%)$ & $\begin{array}{l}\text { Cases, }(\mathrm{n}=432, \\
51.2 \%), \mathrm{n}(\%)\end{array}$ & $\begin{array}{l}\text { Controls }(\mathrm{n}=412, \\
48.8 \%), \mathrm{n}(\%)\end{array}$ & $P$ value \\
\hline \multicolumn{5}{|l|}{ Demographics } \\
\hline Age group (years) & & & & $<.001$ \\
\hline$<15$ & 607 (71.9) & $358(82.9)$ & $249(60.4)$ & \\
\hline$\geq 15$ & $237(28.1)$ & $74(17.1)$ & $163(39.6)$ & \\
\hline Gender & & & & .74 \\
\hline Male & $437(51.8)$ & $226(52.3)$ & $211(51.2)$ & \\
\hline Female & $407(48.2)$ & $206(47.7)$ & $201(48.8)$ & \\
\hline Residency & & & & $<.001$ \\
\hline Rural/semiurban & $464(55)$ & $271(62.7)$ & $193(46.8)$ & \\
\hline Urban & $380(45)$ & $161(37.3)$ & $219(53.2)$ & \\
\hline \multicolumn{5}{|l|}{ Characteristics } \\
\hline Previous displacement & & & & $<.001$ \\
\hline Yes & $493(58.4)$ & $332(76.9)$ & $161(39.1)$ & \\
\hline No & $351(41.6)$ & $100(23.1)$ & $251(60.9)$ & \\
\hline Building material of the house & & & & $<.001$ \\
\hline Clay & $117(13.9)$ & $81(18.8)$ & $36(8.7)$ & \\
\hline Block/brick & $727(86.1)$ & $351(81.3)$ & $376(91.3)$ & \\
\hline Indoor space & & & & $<.001$ \\
\hline Not painted & $178(21.1)$ & $117(27.1)$ & $61(14.8)$ & \\
\hline Painted & $666(78.9)$ & $315(72.9)$ & $351(85.2)$ & \\
\hline Electricity supply (hours per day) & & & & $<.001$ \\
\hline$<12$ & $394(46.7)$ & $236(54.6)$ & $158(38.3)$ & \\
\hline$\geq 12$ & $450(53.3)$ & $196(45.4)$ & $254(61.7)$ & \\
\hline Animals & & & & $<.001$ \\
\hline Dogs only & $14(1.7)$ & $8(1.9)$ & $6(1.5)$ & \\
\hline Chickens only/sheep only/both & $254(30.1)$ & $169(39.1)$ & $85(20.6)$ & \\
\hline Mixture of dogs and sheep or dogs and chickens & $134(15.9)$ & $93(21.5)$ & $41(10)$ & \\
\hline No animals & $442(52.4)$ & $162(37.5)$ & $280(68)$ & \\
\hline Distance of animals from house (meters) ${ }^{a}$ & & & & $<.001$ \\
\hline All & $436(51.7)$ & $301(69.7)$ & $135(32.8)$ & \\
\hline$<100$ & $305(70)$ & $253(84.1)$ & $52(38.5)$ & \\
\hline $100-300$ & $111(25.4)$ & $39(13)$ & $72(53.3)$ & \\
\hline$>300$ & $20(4.9)$ & $9(3)$ & $11(8.1)$ & \\
\hline Presence of rodents in the house & & & & $<.001$ \\
\hline Yes & $648(76.8)$ & $388(89.8)$ & $260(63.1)$ & \\
\hline No & $196(23.2)$ & $44(10.2)$ & $152(36.9)$ & \\
\hline Use of fogging & & & & $<.001$ \\
\hline Yes & $127(15)$ & $85(29)$ & $42(10.2)$ & \\
\hline Unknown & $220(26.1)$ & $104(24.1)$ & $116(28.2)$ & \\
\hline No & 497 (58.9) & $243(56.3)$ & $254(61.7)$ & \\
\hline Use of bed net & & & & $<.001$ \\
\hline
\end{tabular}




\begin{tabular}{llll}
\hline Characteristic & Total $(\mathrm{N}=844), \mathrm{n}(\%)$ & $\begin{array}{l}\text { Cases, }(\mathrm{n}=432, \\
51.2 \%), \mathrm{n}(\%)\end{array}$ & $\begin{array}{l}\text { Controls }(\mathrm{n}=412, \quad P \text { value } \\
48.8 \%), \mathrm{n}(\%)\end{array}$ \\
\hline Yes & $108(12.7)$ & $55(12.7)$ & $53(12.8)$ \\
Unknown & $127(15)$ & $67(15.5)$ & $60(14.5)$ \\
No & $609(72.3)$ & $310(71.7)$ & $299(72.5)$ \\
Sleeping habits & & $318(73.6)$ & $350(84.9)$ \\
Inside the house & $668(79.1)$ & $15(3.6)$ & $4(1)$ \\
$\quad$ Outside the house & $19(2.2)$ & $99(22.9)$ & $58(14.1)$ \\
Inside/outside the house & $157(18.6)$ & 5.001 \\
\hline
\end{tabular}

aPercentages in this category are calculated based on the "All" values.

Table 2. The odds ratios, attributable fractions, and 95\% confidence intervals of the modifiable risk factors.

\begin{tabular}{|c|c|c|}
\hline Risk factor & Odds ratio $(95 \% \mathrm{CI})$ & Attributable fraction $(\%)(95 \% \mathrm{CI})$ \\
\hline Displacement & $5.18(3.84$ to 6.98$)$ & $80.6(73.7$ to 85.8$)$ \\
\hline Clay house & $2.41(1.59$ to 3.66$)$ & $58.5(36.7$ to 72.7$)$ \\
\hline Residence in rural region & $1.91(1.45$ to 2.51$)$ & $47.6(31$ to 60.1$)$ \\
\hline Unpainted interior & 2.14 (1.51 to 3.02$)$ & $53.3(33.8$ to 66.9$)$ \\
\hline Electricity for $<12$ hours per day & $1.94(1.47$ to 2.55$)$ & 48.30 (31.9 to 60.8$)$ \\
\hline \multicolumn{3}{|l|}{ Animals } \\
\hline Dogs only & $2.30(0.79$ to 6.76$)$ & $56.5(-28.2$ to 85.2$)$ \\
\hline Chickens only/sheep only/both & $3.44(2.48$ to 4.75$)$ & $70.9(59.7$ to 78.9$)$ \\
\hline Mixture of dogs and sheep or dogs and chickens & $3.92(2.59$ to 5.94$)$ & 74.5 (61.4 to 83.2$)$ \\
\hline \multicolumn{3}{|l|}{ Distance of animals from the house (meters) } \\
\hline$<100$ & $5.95(2.35$ to 15.07$)$ & $83.2(57.4$ to 93.4$)$ \\
\hline $100-300$ & $0.66(0.25$ to 1.73$)$ & $-51.5(-3$ to 42.1$)$ \\
\hline Presence of rodents in the house & 5.15 (3.56 to 7.47$)$ & $80.6(71.9$ to 86.6$)$ \\
\hline \multicolumn{3}{|l|}{ Use of fogging } \\
\hline Yes & $2.11(1.40$ to 3.19$)$ & $52.6(28.6$ to 68.6$)$ \\
\hline Unknown & $2.25(1.43$ to 3.56$)$ & 55.5 (30.1 to 71.9$)$ \\
\hline \multicolumn{3}{|l|}{ Use of bed net } \\
\hline Yes & $1.72(1.08$ to 2.72$)$ & $41.9(7.4$ to 63.2$)$ \\
\hline Unknown & $1.49(0.86$ to 2.60$)$ & $32.9(-16.3$ to 61.5$)$ \\
\hline \multicolumn{3}{|l|}{ Sleeping habits } \\
\hline Outside the house & $4.01(1.32$ to 12.19$)$ & $75.1(24.2$ to 91.8$)$ \\
\hline Inside/outside the house & 2.07 (1.43 to 3$)$ & $51.7(30.1$ to 66.7$)$ \\
\hline
\end{tabular}

\section{Discussion}

\section{Principal Findings}

To our knowledge, this is the first large population-based case-control study performed in Iraq to determine the risk factors of $\mathrm{CL}$ and the impact of changing modifiable risk factors. We identified the main domestic and behavioral characteristics associated with increasing the odds of contracting CL, which provides a guide for preventive and control measures.

The main modifiable risk factors were displacement, having animals within 100 meters of the house, and sleeping outside the house. In fact, the exposure of $70 \%$ to $80 \%$ of the cases was associated with displacement, animals in the house, animals within 100 meters of the house, and sleeping outside. In contrast, preventive measures, such as bed net use and fogging, were not successful in preventing CL, as both were associated with increased odds of having CL. In fact, assuming a causal relationship and no bias, the data show that approximately $42 \%$ of the cases who used a bed net and $10 \%$ of the cases who reported fogging would not have contracted CL if they had not 
used bed nets or fogging. This finding could be explained by inappropriate timing of fogging, that is, fogging occurred after people returned to liberated areas and had already been bitten by sand flies. In addition, fogging may have been performed in the afternoon, when sand flies are inactive, and the flies were consequently not affected. Bed net use was also not an effective measure of preventing CL, possibly because the patients went to bed late, when the sand flies were not active, and therefore had already been bitten.

The findings in our study regarding displacement, poor housing conditions, and sleeping outside the house agree with findings from studies of risk factors in developing and developed countries [15],[16] (retracted), [17]. Displacement increases individuals' risk of exposure to environmental and personal risk factors of developing CL. In addition, areas from which people are displaced, usually war zones, provide a suitable culture for the growth of both vectors and reservoirs of CL because of the accumulation of wastes and the destruction of infrastructure, such as sewage systems [7]. These findings suggest that preventing CL requires a multifaceted approach that focuses on modifying environmental, domestic, and peridomestic characteristics and on changing human behaviors. Our findings are similar to findings from studies of risk factors of CL in Morocco [18,19], Spain [20], and Ghana [20].

Our study has several strengths. First, it is the first large population-based case-control study of a leishmaniasis outbreak. We identified the main risk factors and their attributable fractions, providing an estimate of the public health impact of the disease. In addition, the findings from our study help to guide preventive and control measures as to the timing of fogging, keeping animals outside houses, painting indoors, and sleeping inside houses.

Our study also has a few limitations. First, the duration of the study was limited, as all data were collected in only 4 days; this led to missing information for some of the variables in the original sample, and they were thus excluded. Second, two important variables were missed, namely, time of fogging and time of sleep, which led us to hypothesize that both actions were undertaken at the wrong time and consequently both surfaced as risk factors rather than preventive factors for the disease. Third, the hazardous security situation limited the movement of the team to only safe areas, which could have obscured other risk factors we are not aware of. Finally, no species were identified from the patients, reservoirs, or vectors to establish the linking of the transmission cycle; therefore, the link is only epidemiologic. None of these limitations could have affected findings from our study; nevertheless, they are worth mentioning to direct future studies in Iraq regarding variables to consider.

\section{Conclusions and Recommendations}

CL is an important public health problem in Iraq, especially in Diyala Province. Most of the cases in our study could have been prevented if they were not exposed to displacement, animals inside the house, animals within 100 meters of the house, or rodents in the house. In addition, the timing of fogging and using bed nets is an important consideration. Prevention and control of CL require a multifaceted approach that relies on changing environmental conditions, housing conditions, and human behavior. Fogging and bed net use were not effective because the underlying housing characteristics and human behavior provided a good culture for the disease.

We recommend conducting a study to identify the species, reservoirs, and vectors of CL in Iraq, studying vector behaviors before applying environmental control measures, and educating the public on how and when to use bed nets and accompany their use with behavioral changes, such as using insect repellents and wearing long sleeves. Furthermore, we recommend studying vector and reservoir behaviors before implementing control measures. In addition, we recommend implementing preventive measures, such as fogging and rodent control, in abandoned areas before people resettle after displacement.

\section{Acknowledgments}

This study was funded for transportation and data collection by the Eastern Mediterranean Public Health Network (EMPHNET). We thank them for their financial support of this study.

\section{Conflicts of Interest}

None declared.

\section{References}

1. Framework for action on cutaneous leishmaniasis in the Eastern Mediterranean Region 2014 - 2018. World Health Organization. 2014. URL: https://apps.who.int/iris/handle/10665/120003?locale-attribute=ru\& [accessed 2021-07-07]

2. de Araujo AR, Portela NC, Feitosa APS, da Silva OA, Ximenes RAA, Alves LC, et al. Risk factors associated with American cutaneous leishmaniasis. Rev Inst Med Trop S Paulo 2016;58:58-86. [doi: 10.1590/s1678-9946201658086]

3. Mursalin SM, Sheikh Ali SA, Crilly J, Bino S. Leishmaniasis Gap Analysis Report and Action Plan: Strengthening the Epidemiologial Surveillance, Diagnosis and Treatment of Visceral and Cutaneous Leishmaniasis in Albania, Jordan and Pakistan. Connecting Organisations for Regional Disease Surveillance (CORDS). 2015 Dec 30. URL: http://www. mecidsnetwork.org/sites/default/files/FINAL\%20Leishmaniasis\%20Gap\%20Analysis\%20Report\%20and\%20Action\%20Plan. pdf [accessed 2021-07-08]

4. Alvar J, Vélez ID, Bern C, Herrero M, Desjeux P, Cano J, WHO Leishmaniasis Control Team. Leishmaniasis worldwide and global estimates of its incidence. PLoS One 2012;7(5):e35671 [FREE Full text] [doi: 10.1371/journal.pone.0035671] [Medline: 22693548] 
5. Manual for case management of cutaneous leishmaniasis in the WHO Eastern Mediterranean Region. World Health Organization Regional Office for the Eastern Mediterranean. 2014. URL: https://apps.who.int/iris/handle/10665/120002 [accessed 2021-07-07]

6. Leishmaniasis, resources: Iraq. World Health Organization. URL: http://www.who.int/leishmaniasis/resources/IRAQ.pdf [accessed 2021-07-07]

7. Oryan A, Akbari M. Worldwide risk factors in leishmaniasis. Asian Pac J Trop Med 2016;9(10):925-932 [FREE Full text] [doi: 10.1016/j.apjtm.2016.06.021] [Medline: 27794384]

8. Sunyoto T, Verdonck K, El Safi S, Potet J, Picado A, Boelaert M. Uncharted territory of the epidemiological burden of cutaneous leishmaniasis in sub-Saharan Africa-A systematic review. PLoS Negl Trop Dis 2018 Oct;12(10):e0006914 [FREE Full text] [doi: 10.1371/journal.pntd.0006914] [Medline: 30359376]

9. Parasites-leishmaniasis: epidemiology and risk factors. US Centers for Disease Control and Prevention. URL: https://www. cdc.gov/parasites/leishmaniasis/epi.html [accessed 2021-07-07]

10. Salam N, Al-Shaqha WM, Azzi A. Leishmaniasis in the Middle East: incidence and epidemiology. PLoS Negl Trop Dis 2014 Oct;8(10):e3208 [FREE Full text] [doi: 10.1371/journal.pntd.0003208] [Medline: 25275483]

11. Hijjawi N, Kanani KA, Rasheed M, Atoum M, Abdel-Dayem M, Irhimeh MR. Molecular diagnosis and identification of Leishmania species in Jordan from saved dry samples. Biomed Res Int 2016;2016:6871739 [FREE Full text] [doi: 10.1155/2016/6871739] [Medline: 27403435]

12. Yadon ZE, Rodrigues LC, Davies CR, Quigley MA. Indoor and peridomestic transmission of American cutaneous leishmaniasis in northwestern Argentina: a retrospective case-control study. Am J Trop Med Hyg 2003 May;68(5):519-526. [doi: 10.4269/ajtmh.2003.68.519] [Medline: 12812336]

13. Ullah K, Khan NH, Sepúlveda N, Munir A, Wahid S. Assessing incidence patterns and risk factors for cutaneous leishmaniasis in Peshawar Region, Khyber Pakhtunkhwa, Pakistan. J Parasitol 2016 Oct;102(5):501-506. [doi: 10.1645/15-919] [Medline: 27310301]

14. Leishmaniasis fact sheet. World Health Organization. 2021 May 20. URL: http://www.who.int/mediacentre/factsheets/ fs375/en/ [accessed 2021-07-07]

15. Ershadi MY, Zahraei-Ramazani A, Akhavan A, Jalali-Zand A, Abdoli H, Nadim A. Rodent control operations against zoonotic cutaneous leishmaniasis in rural Iran. Ann Saudi Med 2005 Jul;25(4):309-312 [FREE Full text] [doi: 10.5144/0256-4947.2005.309] [Medline: 16212124]

16. Sharma U, Singh S. Insect vectors of Leishmania: distribution, physiology and their control. Retracted in: J Vector Borne Dis 2008 Dec;45(4):255-272 [FREE Full text] [Medline: 19248652]

17. Oré M, Sáenz E, Cabrera R, Sanchez JF, De Los Santos MB, Lucas CM, et al. Outbreak of cutaneous leishmaniasis in Peruvian military personnel undertaking training activities in the Amazon Basin. Am J Trop Med Hyg 2015 Aug;93(2):340-346 [FREE Full text] [doi: 10.4269/ajtmh.15-0107] [Medline: 26078320]

18. Gijón-Robles P, Abattouy N, Merino-Espinosa G, El Khalfaoui N, Morillas-Márquez F, Corpas-López V, et al. Risk factors for the expansion of cutaneous leishmaniasis by Leishmania tropica: possible implications for control programmes.

Transbound Emerg Dis 2018 Dec;65(6):1615-1626. [doi: 10.1111/tbed.12914] [Medline: 29806200]

19. El Alem MMM, Hakkour M, Hmamouch A, Halhali M, Delouane B, Habbari K, et al. Risk factors and prediction analysis of cutaneous leishmaniasis due to Leishmania tropica in Southwestern Morocco. Infect Genet Evol 2018 Jul;61:84-91. [doi: 10.1016/j.meegid.2018.03.017] [Medline: 29578084]

20. Ibarra-Meneses AV, Carrillo E, Nieto J, Sánchez C, Ortega S, Estirado A, et al. Prevalence of asymptomatic Leishmania infection and associated risk factors, after an outbreak in the south-western Madrid region, Spain. Euro Surveill 2019;24(22):1800379 [FREE Full text] [doi: 10.2807/1560-7917.es.2019.24.22.1800379] [Medline: $\underline{31164191]}$

\section{Abbreviations \\ CL: cutaneous leishmaniasis \\ EMPHNET: Eastern Mediterranean Public Health Network \\ OR: odds ratio}

Edited by E Meinert; submitted 26.02.21; peer-reviewed by R Al-Dubaiee, $R$ Taher, A Nassar; comments to author $16.04 .21 ;$ revised
version received 25.04.21; accepted 16.05.21; published 30.07.21
Please cite as:
Lehlewa AM, Khaleel HA, Lami F, Hasan SAF, Malick HA, Mohammed RH, Abdulmottaleb QA
Impact of Modifiable Risk Factors on the Occurrence of Cutaneous Leishmaniasis in Diyala, Iraq: Case-Control Study
JMIRx Med 2021;2(3):e28255
URL: $\underline{\text { https://med.jmirx.org/2021/3/e28255 }}$
doi: $10.2196 / 28255$
PMID:


(C)Asaad Mahdi Lehlewa, Hanan Abdulghafoor Khaleel, Faris Lami, Saif Aldeen Falah Hasan, Hasanain Asmail Malick, Razzaq Hashim Mohammed, Qais Abdulazziz Abdulmottaleb. Originally published in JMIRx Med (https://med.jmirx.org), 30.07.2021. This is an open-access article distributed under the terms of the Creative Commons Attribution License (https://creativecommons.org/licenses/by/4.0/), which permits unrestricted use, distribution, and reproduction in any medium, provided the original work, first published in JMIRx Med, is properly cited. The complete bibliographic information, a link to the original publication on https://med.jmirx.org/, as well as this copyright and license information must be included. 